Richard M. K. Adanu • John O. L. De Lancey •

Janis M. Miller - Abena Asante

\title{
The physical finding of stress urinary incontinence among African women in Ghana
}

Received: 27 July 2005 / Accepted: 18 December 2005

(C) International Urogynecology Journal 2005

\begin{abstract}
The aim of this study is to determine the proportion of women with the physical sign of stress urinary incontinence in a sample of Ghanaian women. Two hundred randomly selected women from attendants at a convenience selected ultrasound clinic were interviewed about symptoms of urinary incontinence. A paper towel test was performed to objectively demonstrate the physical sign of stress urinary incontinence as leakage on coughing. Forty-two percent of the women had a positive paper towel test. The two major symptoms reported by the women with positive paper towel test were (1) loss of urine while waiting to use the toilet (48.2\%) and (2) loss of urine on coughing $(43.4 \%)$ in daily life. The physical sign of stress urinary incontinence could be present in up to $42 \%$ of Ghanaian women.
\end{abstract}

Keywords Urinary incontinence - Stress incontinence · Women · Ghana $\cdot$ Africa

R. M. K. Adanu ( $\triangle)$

Department of Obstetrics and Gynecology,

University of Ghana Medical School,

P.O. Box GP4236, Accra, Ghana

e-mail: rmadanu@yahoo.com

J. O. L. De Lancey

University of Michigan Medical Center,

L4000 Women's Hospital,

1500E Medical Center Drive,

Ann Arbor, MI 48109-0276, USA

J. M. Miller

University of Michigan Medical Center and School of Nursing,

400 N. Ingalls, Division 2,

Ann Arbor, MI 48109-0482, USA

A. Asante

Department of Community Health,

University of Ghana Medical School,

P.O. Box GP 4236, Accra, Ghana

\section{Introduction}

Urinary incontinence is a common symptom in women, and it has been shown to have major physical, social, and psychological effects [1]. In Ghana and in most of subSaharan Africa, the major concern is about urinary incontinence resulting from obstetric fistulae [2]. The subject of stress urinary incontinence is not often discussed, because the condition is assumed to be rare. This assumption has been supported by studies from some African countries [3].

There has been considerable interest in racial differences in urinary incontinence in the United States, with a presumption that urinary incontinence, specifically stress urinary incontinence is uncommon among African-American women [4-6]. This presumption raises the need for more studies among both African and African-American women to clearly determine whether there are major genetic factors that affect the occurrence of stress incontinence.

The physical finding of stress urinary incontinence is easily assessed as demonstrable leakage instigated by increased intra-abdominal pressure in the presence of a full bladder. The paper towel test [7] is a simple test that has been described to demonstrate stress urinary incontinence. In this study, the paper towel test [7] was performed among Ghanaian women awaiting an ultrasound examination.

The aim of this study is to estimate the prevalence of the physical sign of stress urinary incontinence among a sample of Ghanaian women and to describe the incontinence symptoms they report.

\section{Materials and methods}

The study was carried out among a sample of patients at a gynecology ultrasound clinic, because these women present with a full bladder which is a necessary condition in testing for the demonstration of the physical sign of stress incontinence. The ultrasound clinic chosen was one wherein the first author worked. 
A review of prior clinic records showed that approximately ten eligible women would be seen on each day of a 5 -day week. The study was designed to run for 2 months to select a subset of women for inclusion; 200 random numbers between 1 and 400 were generated using Epitable from Epi Info version 6. Eligible women who came to the clinic from November 1, 2003 were numbered consecutively, and those whose numbers corresponded with the random numbers were recruited for the study. The study continued until January 15, 2004.

Approval for the study was given by the management team of the ultrasound clinic. The study design and its aims were explained to the women on an individual basis, and enrollment occurred after a woman consented to participate. Women were excluded if they were pregnant, experiencing vaginal bleeding from any cause, had an uncomfortably full bladder, had been diagnosed with a vesicovaginal fistula, or if they were acutely ill. Women were included in the study if ultrasound was indicated for other common reasons including infertility, uterine fibroids, adnexal masses, and pelvic pain. The interview and paper towel test were performed after the ultrasound examination so that no woman with an empty bladder would be included in the sample. None of the selected women declined to participate in the study.

All the participants were interviewed using a 14-item questionnaire (see Appendix). The questionnaire had sections on sociodemographic characteristics, menstrual history, past obstetric history, use of medication, medical and surgical history, and symptoms of urinary incontinence. The questionnaire was developed by the first three authors after the discussion of the different circumstances surrounding urine leakage and the predisposing factors of stress urinary incontinence. Questions on the incontinence symptoms were obtained from the incontinence screening questionnaire designed by Gunthorpe et al. [8]. The first and fourth authors discussed the translation of the questionnaire into the major Ghanaian languages. To ensure uniformity, all the interviews were performed by the fourth author. Each of the women was interviewed in a language of her choice to avoid difficulty in understanding the questions.
After the interview, the physical finding of stress incontinence was elicited by using a standard paper towel test as originally described by Miller et al. [7]. The participants were directed to hold a trifold brown paper towel (Item \#219-24, Handifold Towels, Fort Howard Corp., Green Bay, WI) lightly against the perineum and cough three times while standing. The paper towel was then returned to the authors, and any wet area was noted and the outline marked with a ballpoint pen. The paper towels were reexamined after drying. Wetness due to urine was identified by being outlined with the ballpoint pen without any associated staining. Areas marked which contained a stain were considered to be due to vaginal secretions. Only the results with wetness due to urine were recorded as having a positive paper towel test.

To have an estimate of the type of urinary incontinence, respondents who complained of loss of urine on coughing but no urgent need to pass urine with fear of leakage were classified as having stress urinary incontinence, while those complaining of an urgent need to pass urine with fear of leakage but no leakage of urine on coughing were classified as having urge incontinence. A combination of both symptoms indicated the presence of mixed incontinence. The other symptoms on the questionnaire were not considered in this classification, because their presence does not rule out the presence of the three gynecological types of incontinence.

The results of the interview and paper towel test were coded and analyzed using Stata 8 (StataCorp College Station, TX). The chi-square test, two-tailed $t$ test, and Wilcoxon rank sum test were used for group comparisons. Simple and multiple logistic regressions were used to determine the predictors of a positive paper towel test. Model testing was done using the Pearson's goodness of fit test.

\section{Results}

The 200 respondents were between 17 and 70 years of age, with a mean (standard deviation) age of 39.1 (11.9) years. Forty $(20.0 \%)$ of the respondents were postmenopausal.
Table 1 Comparison of selected Ghanaian women attending an ultrasound clinic based on presence of a physical sign of stress incontinence

\begin{tabular}{lccc}
\hline Characteristic & Positive test & Negative test & $p$ value \\
\hline Mean age (standard deviation) & $38.8(11.4)$ & $39.4(10.9)$ & 0.71 \\
Postmenopausal & $21 / 82(25.6 \%)$ & $30 / 117(25.6 \%)$ & 1.00 \\
On regular hospital medication & $19 / 83(22.9 \%)$ & $29 / 117(24.8 \%)$ & 0.76 \\
On herbal medication & $18 / 83(21.7 \%)$ & $14 / 117(12.0 \%)$ & 0.07 \\
No vaginal delivery & $31 / 83(37.4 \%)$ & $38 / 117(32.5 \%)$ & 0.48 \\
Median number of vaginal deliveries & 2 & 2 & 0.36 \\
Median number of cesarean sections & 0 & 0 & 0.72 \\
Median number of symptoms & 1 & 0 & $<0.001$ \\
Ultrasound findings & & & \\
Normal-sized uterus & $48 / 83(57.8 \%)$ & $69 / 117(60.0 \%)$ & 0.87 \\
Uterine fibroids & $25 / 83(30.1 \%)$ & $31 / 117(26.5 \%)$ & 0.57 \\
Adnexal mass & $10 / 83(12.1 \%)$ & $17 / 117(14.5 \%)$ & 0.67 \\
\hline
\end{tabular}


Table 2 Comparison of symptoms reported by selected Ghanaian women attending an ultrasound clinic according to the finding of the physical sign of stress incontinence
${ }^{a}$ Respondents were asked if they had ever experienced any of these. Some respondents reported more than one symptom

\begin{tabular}{lllc}
\hline Symptom & $\begin{array}{l}\text { Number with positive paper } \\
\text { towel test (percentage) }\end{array}$ & $\begin{array}{l}\text { Number with negative paper } \\
\text { towel test (percentage) }\end{array}$ & $p$ value \\
\hline $\begin{array}{l}\text { Leaked urine while waiting to } \\
\text { use toilet }\end{array}$ & $40(48.2)$ & $29(24.8)$ & 0.001 \\
$\begin{array}{l}\text { Leaked urine on coughing } \\
\text { Leaked urine on way to toilet }\end{array}$ & $36(43.4)$ & $20(17.1)$ & $<0.001$ \\
$\begin{array}{l}\text { Urgent need to pass urine with } \\
\text { fear of leakage }\end{array}$ & $12(10.3)$ & $22(18.8)$ & 0.27 \\
$\begin{array}{l}\text { Leaked urine when could not } \\
\text { go to toilet immediately }\end{array}$ & $20(24.1)$ & $16(19.3)$ & 0.07 \\
$\begin{array}{l}\text { Gone to toilet 'just in case' } \\
\text { Gone to toilet urgently for fear } \\
\text { of leakage }\end{array}$ & $5(4.8)$ & $10(8.6)$ & 0.002 \\
\hline
\end{tabular}

One hundred and forty women $(70.0 \%)$ had delivered before, $9(6.4 \%)$ of these had delivered by cesarean section only, and $16(11.4 \%)$ had a history of at least one cesarean section in addition to vaginal delivery. Fifty-two women $(26.0 \%)$ had known medical or surgical conditions, 48 $(24.0 \%)$ were on regular hospital medication, and 32 $(16.0 \%)$ were on regular herbal medication.

When the paper towel test was performed for the objective demonstration of urine loss, 83 women (41.5\%) had signs of stress incontinence. Of those with a positive paper towel test, $67(80.7 \%)$ had at least one symptom of urinary incontinence. The presence of at least one incontinence symptom on interview was significantly associated with a positive paper towel test $(p<0.001)$.

Table 1 shows the differences between the women with demonstrable stress incontinence and those without. Comparing the women with a positive paper towel test to those with a negative test showed a statistical difference $(p<0.05)$ for the following symptoms: involuntary urine loss on coughing, involuntary urine loss while waiting to use the toilet, and involuntary urine loss when it was not possible to use the toilet immediately.

Among the 200 women, $77(38.5 \%)$ reported no symptoms, $51(25.5 \%)$ complained of one incontinence symptom, and $2(1.0 \%)$ had six symptoms. Table 2 shows the distribution of symptoms of urinary incontinence among the 200 respondents and the proportion of women within each symptom group who had a positive paper towel test. The commonest complaint $(28.0 \%)$ among all the women was of loss of urine on coughing.

The two predominant symptoms reported by the women with a positive paper towel test were involuntary loss of urine while waiting to use the toilet $(48.2 \%)$ and involuntary loss of urine on coughing (43.4\%).

Based on the symptom survey, $45(22.5 \%)$ women had stress incontinence, $17(8.5 \%)$ had urge incontinence, and

Table 3 Crude and adjusted odds ratios of having a positive paper towel test

\begin{tabular}{|c|c|c|c|}
\hline Covariate & Crude odds ratio & Model 1 & Model 2 \\
\hline $\operatorname{Age}^{a}$ & $1.0(0.97-1.02)$ & $1.0(0.97-1.1)$ & $1.0(0.96-1.1)$ \\
\hline Postmenopausal vs premenopausal & $1.0(0.5-1.9)$ & $1.1(0.5-2.7)$ & $1.4(0.6-3.8)$ \\
\hline Vaginal delivery vs no vaginal delivery & $0.8(0.4-1.5)$ & $0.7(0.3-1.5)$ & $0.7(0.3-1.6)$ \\
\hline Number of vaginal deliveries ${ }^{\mathrm{a}}$ & $0.9(0.8-1.1)$ & & \\
\hline Regular hospital medication vs none & $0.9(0.5-1.7)$ & $1.0(0.4-2.5)$ & $0.9(0.4-2.3)$ \\
\hline Regular herbal medication vs none & $2.0(0.9-4.4)$ & $1.4(0.6-3.3)$ & $1.9(0.8-4.8)$ \\
\hline Existing medical condition vs none & $0.8(0.4-1.6)$ & $0.7(0.3-1.6)$ & $0.7(0.3-1.7)$ \\
\hline Number of symptoms ${ }^{\mathrm{a}}$ & $1.7(1.3-2.1)$ & $1.7(1.3-2.2)$ & \\
\hline Leaked urine while waiting to use toilet ${ }^{\mathrm{b}}$ & $2.8(1.5-5.2)$ & & $2.2(1.1-4.4)$ \\
\hline Leaked urine on coughing ${ }^{\mathrm{b}}$ & $3.7(1.9-7.1)$ & & $4.0(1.9-8.4)$ \\
\hline Leaked urine on way to toilet ${ }^{b}$ & $1.5(0.7-2.9)$ & & $0.7(0.3-1.6)$ \\
\hline Urgent need to pass urine with fear of leakage ${ }^{b}$ & $2.1(0.9-4.7)$ & & $0.8(0.3-2.3)$ \\
\hline Leaked urine when could not go to toilet immediately ${ }^{\mathrm{b}}$ & $3.4(1.5-7.7)$ & & $2.8(1.0-7.4)$ \\
\hline Gone to toilet "just in case ${ }^{\mathrm{b}}$ & $3.7(0.7-19.5)$ & & $2.8(0.4-20.1)$ \\
\hline Gone to toilet urgently for fear of leakage ${ }^{b}$ & $1.9(0.4-8.8)$ & & $2.3(0.3-15.2)$ \\
\hline -log likelihood & & -121.7 & -116.4 \\
\hline$p$ value for goodness of fit & & 0.22 & 0.23 \\
\hline
\end{tabular}

Models 1 and 2 are multiple logistic regression models

${ }^{a}$ Modeled as continuous variables

${ }^{\mathrm{b}}$ Compared to respondents without the symptom 
$11(5.5 \%)$ had mixed incontinence. Assuming that only respondents with a positive paper towel test had urinary incontinence, then 29 (14.5\%) suffered from stress incontinence, while $9(4.5 \%)$ and $7(3.5 \%)$ suffered from urge and mixed incontinence, respectively.

There was no statistically significant association between either past obstetric history or menopausal status and the presence of a positive paper towel test. The multiple logistic regression model that included a number of symptoms as a covariate (Table 3 ) showed that only the number of incontinence symptoms was the significant predictor [odds ratio (OR) 1.73, confidence interval (CI) 1.35-2.22] of a positive paper towel test after controlling for the other variables. From the model within which each of the incontinence symptoms was entered separately, complaints of urine loss on coughing while waiting to use the toilet or when the respondent could not use the toilet immediately were the symptoms significantly associated with a positive paper towel test. A complaint of urinary loss on coughing has a fourfold increase in the odds of having a positive paper towel test (CI 1.90-8.40).

\section{Discussion}

Among African women attending an ultrasound clinic who had a full but not uncomfortably full bladder, $42 \%$ of the women had the physical sign of stress incontinence. The number of incontinence symptoms reported by a woman was significantly associated with the presence of the physical sign of stress incontinence. The two main reported incontinence symptoms of these women were involuntary loss of urine while waiting to use the toilet and involuntary loss of urine on coughing.

Urinary incontinence is a well-known condition in Africa, where the devastating obstetric vesicovaginal fistula resulting from obstructed labor [2,9] causes a severity of incontinence rarely seen in more developed countries. Nonfistula urinary incontinence is, however, rarely considered a major problem in the African context. This could be due to the possibility that the severity of both symptoms and psychosocial effects of obstetric fistulae are largely relative to that experienced with stress and urge incontinence, making the latter two problems appear insignificant in comparison. On the other hand, nonfistula urinary incontinence could be a rare problem among African women. Although studies on nonfistula urinary incontinence have mostly been carried out among white women [1], studies in black South-African women suggest that nonfistula incontinence is rare among black African women [3]. There have been no recent studies on nonfistula incontinence in sub-Saharan Africa, but studies from North Africa, suggest that stress incontinence might be more common in Africa than previously thought $[10,11]$.

Our study shows demonstrable stress incontinence in $42.0 \%$ of this sample of Ghanaian women. These women were selected from an ultrasound clinic, because it was the most likely place to find women who had a full bladder that was necessary for the performance of the paper towel test.
The possibility that a higher estimate of demonstrable stress incontinence could be obtained from this sample due to respondents having an uncomfortably full bladder was considered at study inception. The authors attempted to reduce this by finding out from respondents whether they felt comfortable with the level of bladder fullness before the test was performed. The women presenting for ultrasound testing are not completely representative of the general Ghanaian population. However, because no information exists about the frequency with which stress incontinence is demonstrable in African women, these findings provide a working estimate of the prevalence of stress urinary incontinence until the time that financial resources might be available to carry out a populationbased study.

The presence of a positive paper towel test when an individual has coughed can occur in women with stress urinary incontinence as well as those with urge incontinence or mixed incontinence. The prevalence of these different types of gynecological urinary incontinence can be estimated considering reported symptoms among women with a positive paper towel test.

The use of the reported symptoms alone, as was done in the study by Coyne et al. [12], suggests that the prevalence of stress incontinence among this sample of women is $22.5 \%$, with a $36.5 \%$ overall prevalence of nonfistula incontinence. These figures are similar to those reported for Spain [13], Morocco [10], and Tunisia [11]. The figures are similar with the prevalence in the racially mixed group of women studied by Grodstein et al. [6]. The prevalence of nonfistula urinary incontinence in Ghanaian women is however higher than the $21.0 \%$ reported among AfricanAmerican women by Grodstein et al. [6]. The possibility of information bias in our study due to one of the investigators performing the interviews cannot be ruled out. However, the large difference between the prevalence among Ghanaian and African-American women raises questions about the possible interaction between genetics and the environment in the pathogenesis of this type of urinary incontinence. The prevalence of $42.0 \%$ of stress incontinence obtained from the results of the paper towel test is similar to the reported prevalence for France, Germany, and the United Kingdom [13], although the figures for the European countries are based on a symptom survey.

This study did not show the expected increase in the odds of stress incontinence with age, number of vaginal deliveries, or menopausal status. This is probably because the study was designed as a cross-sectional one and not a comparative study. This could lead to inadequate power in detecting differences when comparing groups. For example, a total of 306 respondents would be needed in a retrospective case control study with equal numbers of cases and controls to detect a twofold increase in the odds of stress urinary incontinence when comparing cesarean and vaginal delivery assuming a $30 \%$ cesarean section rate among women without stress incontinence.

In most parts of Africa, urodynamic machines are not available for confirmation of diagnosis and for classifying cases of urinary incontinence. The results of this study and 
its comparison between a positive paper towel test and symptoms of urinary incontinence will be a helpful guide for clinicians without access to urodynamic testing to know how much weight to put on patient reports. The successful use of the paper towel test in this study also shows that this simple test can be used with patients in the African setting. The superiority of this test in testing for urinary incontinence in the dorsal or lithotomy position has been discussed by Miller et al. [7]. Any colored paper towel could be used to demonstrate the presence of urinary incontinence.

This study does show that nonfistula urinary incontinence is probably more common among at least some groups of African women than was previously thought. This finding coupled with the absence of statistical significance in the factors that were theorized to be predictors of a positive paper towel test leads us to suggest further studies to document whether the data support the assumptions that stress urinary incontinence has a different prevalence in African women as compared with women of other racial groups. The results of our study suggest that using the paper towel test alone to screen for urinary incontinence in the African setting could lead to high false positive rates, while a symptom screen alone has low sensitivity. The combination of these two methods would however be a helpful first step for incontinence screening among African women. The finding that the presence of at least one urinary incontinence symptom in $80.7 \%$ of those women with the physical sign of stress incontinence suggests, at minimum, the need for integrating direct questions about urinary incontinence into the gynecological history-taking in Africa to be able to identify cases.

\section{Appendix}

Questionnaire

1. Age

2. Ethnicity

3. Are you still experiencing your menses? Yes No

4. If no, how long has it been since you stopped experiencing your menses? less than six months more than six months

5. Have you ever had any deliveries? Yes No

6. If yes, how many? $\quad \begin{array}{lllll}1 & 2 & 3 & 4 & 5\end{array}$ More than 5 7. What was the mode of delivery of each of your children?

Delivery Spontaneous vaginal Forceps Vacuum Cesarean section
1
2
3
4
5

8. Are there any hospital drugs you take regularly? Yes No 9. If yes, state the name of the drugs
10. Are there any herbal or natural health substances that you use?

11. If yes, state the names

12. Do you have any known medical or surgical condition?

13. If yes, what are they?

14. Have you ever experienced any of the following?

- Leaked urine when you cough, laugh or sneeze

- Leaked urine while on the way to the toilet

- Leaked urine when you had to wait to use the toilet

- Leaked urine when you did not go to the toilet immediately when you first felt the urge

- Felt an urgent need to urinate accompanied by fear of leakage

- Gone to the toilet 'just in case' for fear of leaking urine.

\section{References}

1. Hunskaar S, Burgio K, Diokno AC, Herzog AR, Hjalmas K, Lapitan MC (2002) Epidemiology and natural history of urinary incontinence (UI). In: Abrams P, Cardozo L, Khoury $\mathrm{S}$, Wein A (eds) Incontinence. 2nd International consultation on incontinence. Health Publication, Plymouth, pp 165-201

2. Arrowsmith S, Hamlin EC, Wall LL (1996) Obstructed labor injury complex: obstetric fistula formation and the multifaceted morbidity of maternal birth trauma in the developing world. Obstet Gynecol Surv 51(9):568-574

3. Knobel J (1975) Stress incontinence in the black female. S Afr J Obstet Gynaecol 49:430-432

4. Peacock LM, Wiskind AK, Wall LL (1994) Clinical features of urinary incontinence and urogenital prolapse in a black inner city population. Am J Obstet Gynecol 171(6):1464-1469

5. Jackson RA, Vittinghoff E, Kanaya AM, Miles TP, Restrick HE, Kritchevsky SB, Simonsick EM, Brown JS (2004) Urinary incontinence in elderly women: findings from the Health, Aging, and Body Composition Study. Obstet Gynecol 104 (2):301-307

6. Grodstein F, Fretts R, Lifford K, Resnick N, Curhan G (2003) Association of age race and obstetric history with urinary symptoms among women in the Nurses' Health Study. Am J Obstet Gynecol 189(2):428-434

7. Miller JM, Ashton-Miller JA, de Lancey JOL (1998) Quantification of cough-related urine loss using the paper towel test. Obstet Gynecol 91:705-709

8. Gunthorpe W, Brown W, Redman S (2000) The development and evaluation of an incontinence screening questionnaire for female primary care. Neurol Urodyn 19:595-607

9. Wall LL (1998) Dead mothers and injured wives: the social context of maternal morbidity and mortality among the Hausa of northern Nigeria. Stud Fam Plann 29(4):341-359

10. Mikou F, Abbassi O, Benjelloun A, Matar N, el Mansouri A (2001) Prevalence of urinary incontinence in Moroccan women. Report of 1000 cases. Ann Urol (Paris) 35(5):280-289

11. Keskes J, Khairi H, Ben Said A, Hidar M, Pigne A (1998) Stress urinary incontinence in women. Epidemiologic inquiry. Apropos of 500 cases. J Gynecol Obstet Biol Reprod (Paris) 17 (4):453-460

12. Coyne KS, Zhou Z, Thompson C, Versi E (2003) The impact on health-related quality of life of stress, urge and mixed urinary incontinence. BJU Int 92:731-735

13. Hunskaar S, Lose G, Sykes D, Voss S (2004) The prevalence of urinary incontinence in women in four European countries. BJU Int 93:324-330 